\title{
The Influence of Evaluation Subject Visual Perception and Fitting Experience on Consumer Preference for Body-Enhancing Garment
}

\author{
Yan Cui ${ }^{1,2,3}$, Yuqian Dai ${ }^{1,3}$, and Xiaogang Liu ${ }^{1,3 *}$ \\ ${ }^{1}$ College of Fashion and Design, Donghua University, Shanghai 200051, China \\ ${ }^{2}$ Cornell University, Fiber Science and Apparel Design, Ithaca, NY, USA \\ ${ }^{3}$ Shanghai Style Fashion Design \& Value Creation Knowledge Service Center, Donghua University, \\ Shanghai 200051, China
}

\section{Keywords: stereo vision, body-enhancing, apparel design, consumer preference}

Purpose and significance. In women's dress market, slim clothing has always been a major category. Past research showed women consumers pay close attention to their body shaping ability of clothing (Rahman, 2011; Aqueveque, 2006; Olson, 1976, Agost \& Vergara, 2014). Most of the females do not believe their body images are good enough, in order to be more attractive, they would prefer to refine appearances through attires (JT. Fan, Yu, \& Hunter, 2004). However, existing research on clothing consumer preference mainly centers on the relationship with price, place of origin, and colorways. For contouring garments, limited studies have been conducted to explore the consumer's visual perspective and the impact of try-on experience on consumer preferences. This study investigates the influence of evaluation subject visual perception and fitting experience on consumer preference for body-enhancing garment and offers managerial implications for similar products.

Sample. The test garments used in this research were a pair of denim jeans with body-shape contouring ability (J1) and another one with normal design (J2). The design of $\mathbf{J} 1$ combined a series of anatomical shadows of ideal body image with washing area and optical illusion patterns to optimize wearer' s body shape on visual perception. Questionnaires were issued by a professional online questionnaire collection website. A total of 208 respondents were collected in this research. After deleting invalid responses (straight-lining answers, missing values, or obvious illogical answers), we collected a total of 197 valid respondents (94.71\% return rate). All participants were females. They were recruited from universities in Yangtze River delta area either on campuses or via personal contact by researchers. Demographics were collected, including age (under $20=48.45 \% ; 20-25=48.45 \% ; 25-30=3.09 \%$ ), education level (high school $=2.06 \%$, undergraduate or college $=57.73 \%$, postgraduate $=38.14 \%$, doctoral degree and above $=2.06 \%$ ), and other basic information.

Methodology. The way of products display affects consumers' perceptions and psychological feelings directly. Comments or compliments from others would influence the selfsatisfaction of social individuals. Subjects feel their actual-self state were closer to ought-self state, and this would pass on this satisfaction to the clothing they wear, thereby consumers' satisfaction towards testing garments were increased (Higgins, 1987). Meanwhile, try-on experience provides consumers with interactive and perceived opportunities, consumer

Published under a Creative Commons Attribution License (https://creativecommons.org/licenses/by/4.0/), which permits unrestricted use, distribution, and reproduction in any medium, provided the original work is properly cited.

ITAA Proceedings, \#76 - https: //itaaonline.org 
purchasing decisions are positively correlated with satisfaction. Based on previous research, the final questionnaire was organized into two sections: Body-shape enhancing ability of garment (BSEA) and consumers' behavior and preference (CBP). BSEA was measured using three cues extracted from depth perception theory (Ramachandran, 1988). Respondents were asked to finish the questionnaires in two stages: observation stage and try-on stage. They were asked to answer twice for the CBP part (observation stage $=\mathrm{CBPB}$, after trying on=CBPA). $\mathrm{CBP}$ was measured using four matrices adapted and modified from the Kang' (2013) study. Five-point Likert scale questions were used in this survey combining with Single choice question. Following hypotheses were developed: for garments with lifting, contouring and slimming benefits: H1) the bodyenhancing ability of garment in mirror-observation is better than self-observation. H2) bodyenhancing ability of garment is positively affected consumer preference and purchase intention. H3) three-dimensional form of garment will have a better effect on consumer preference than two-dimensional display.

Results and Conclusion. H1 addressed that visual angle would influence body slimming ability of garments. As expected, the result of Paired T-Test shown that mirror observation (Mean $=1.74 \pm 0.53$ ) for $\mathrm{J} 1$ was significantly stronger than self-observation (Mean=2.05 \pm 0.60 , $\mathrm{t}=$ $5.57, \mathrm{P}<0.01$ ), but the results were not significantly different on $\mathrm{J} 2$. For other's observation feedback, J1 had shown a higher score than J2, which implied J1 would make subjects look skinny. Thus, H1 was accepted within 99\% confidence interval. For J1, Pearson's correlation coefficient (r) of consumer preference (CBPA3) and three body-contouring cues (BSEA1, 2, 3) were strong and positive: CBPA3 and BSEA1 $(\gamma=0.416, \mathrm{P}<0.01), \mathrm{CBPA} 3$ and BSEA2 $(\gamma=0.503, \mathrm{P}<0.01), \mathrm{CBPA} 3$ and BSEA3 $(\gamma=0.447, \mathrm{P}<0.01)$. However, the results were relatively insignificant among all the cues for $\mathrm{J} 2$. Therefore, garments with body-contouring effect had a positive correlation with consumer preference and purchase intention. H3 was supported by the result analysis from Paired T-Test analysis between CBPA and CBPB, the loading score of consumer preference for $\mathrm{J} 1$ was higher than $\mathrm{J} 2$. After the try-on experience, both of the consumer's visual differences, self-cultivation ability and purchase intention between J1 and $\mathrm{J} 2$ were increased. Also, consumers were willing to spend more money to buy test products. Furthermore, it showed that BESA jeans had an enhanced ability to optimize the figure after tryon stage. The comprehensive perspective of self-cultivation apparel gave consumers a higher quality product perception. Consequently, consumer preferences and increased willingness to buy. However, the difference in J2 was insignificant.

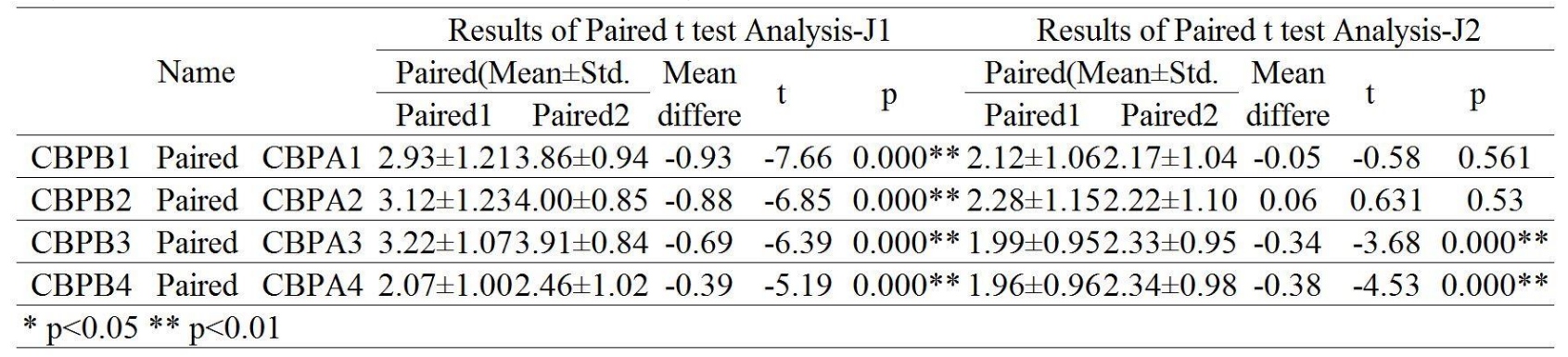

Page 2 of 4

Published under a Creative Commons Attribution License (https://creativecommons.org/licenses/by/4.0/), which permits unrestricted use, distribution, and reproduction in any medium, provided the original work is properly cited.

ITAA Proceedings, \#76 - https: //itaaonline.org 
Implications. This study reveals that different visual perspectives can affect bodycontouring ability of garments. Consumers' mirror observations are superior to self-observation perspectives, mainly because mirrors can reflect a more complete body shape, while selfobserved body images were relatively simple. Visual cognition in the mirror image delivered an intensive body slimming effect, but there was an insignificant difference for normal garments in this property. The result also supported the research of Peck and Wiggins (2006). Furthermore, contouring garments were correlated with consumers' physical satisfaction, which could further improve consumer purchase desire. These findings were in line with the earlier surveys (Osmud Rahman, 2011).

\section{References}

Agost, M. J., \& Vergara, M. (2014). Relationship between meanings, emotions, product preferences and personal values. Application to ceramic tile floorings. Applied ergonomics, 45(4), 1076-1086.

Aqueveque, C. (2006). Extrinsic cues and perceived risk: the influence of consumption situation. Journal of Consumer Marketing, 23(5), 237-247.

Cardozo, R. N. (1965). An experimental study of customer effort, expectation, and satisfaction. Journal of marketing research, 2(3), 244-249.

DeLong, M., LaBat, K., Nelson, N., Koh, A., \& Kim, Y. (2002). Global products, global markets: Jeans in Korea and the United States. Clothing and Textiles Research Journal, 20(4), 238245.

Fan, J., Yu, W., \& Hunter, L. (2004). Clothing appearance and fit: Science and technology. Elsevier.

Grewal, D., Monroe, K. B., \& Krishnan, R. (1998). The effects of price-comparison advertising on buyers' perceptions of acquisition value, transaction value, and behavioral intentions. Journal of marketing, 62(2), 46-59.

Higgins, E. T. (1987). Self-discrepancy: a theory relating self and affect. Psychological review, 94(3), 319.

Hsu, H. J., \& Burns, L. D. (2002). Clothing evaluative criteria: A cross-national comparison of Taiwanese and United States consumers. Clothing and Textiles Research Journal, 20(4), $246-252$.

Olson, J. C., \& Jacoby, J. (1972). Cue utilization in the quality perception process. ACR Special Volumes.

Patterson, P. G., \& Spreng, R. A. (1997). Modelling the relationship between perceived value, satisfaction and repurchase intentions in a business-to-business, services context: an empirical examination. International Journal of service Industry management, 8(5), 414434.

Peck, J., \& Wiggins, J. (2006). It just feels good: Customers' affective response to touch and its influence on persuasion. Journal of Marketing, 70(4), 56-69.

Page 3 of 4

(c) 2019 The author(s). Published under a Creative Commons Attribution License

(https://creativecommons.org/licenses/by/4.0/), which permits unrestricted use, distribution, and reproduction in any medium, provided the original work is properly cited.

ITAA Proceedings, \#76 - https://itaaonline.org 
Rahman, O. (2011). Understanding consumers' perceptions and buying behaviours: Implications for Denim Jeans Design. Journal of Textile and Apparel, Technology and Management, 7(1).

Rahman, O., Zhu, X., \& Liu, W. S. (2008). A study of the pyjamas purchasing behaviour of Chinese consumers in Hangzhou, China. Journal of Fashion Marketing and Management: An International Journal, 12(2), 217-231.

Ramachandran, V. S. (1988). Perception of shape from shading. Nature, 331(6152), 163.

Woodruff, R. B. (1997). Customer value: the next source for competitive advantage. Journal of the academy of marketing science, 25(2), 139.

Published under a Creative Commons Attribution License (https://creativecommons.org/licenses/by/4.0/), which permits unrestricted use, distribution, and reproduction in any medium, provided the original work is properly cited.

ITAA Proceedings, \#76 - https://itaaonline.org 